Send your letters to the Editor, British

Dental Journal, 64 Wimpole Street, London

W1G8YS E-mail bdj@bda.org

Priority will be given to letters less than 500

words long. Authors must sign the letter,

which may be edited for reasons of space.

\section{Outdated definition}

Sir, I wholeheartedly agree with S. J. Davies that the definition of the term 'malocclusion' is outdated and in need of revision (BDJ 2007; 202: 519-520). As a professor I formulated the following definition for teaching orthodontic postgraduates: 'A malocclusion is a solution for a complex, adaptive system to remain in equilibrium'. ${ }^{1}$

The complexity referred to above is twofold: first, structural complexity is in-built in the craniofacial system, which comprises teeth, bone, muscles, joints, soft tissues and functional spaces. Second, mathematical complexity is in-built in the craniofacial system due to any permutation or combination of genes being inherited, and expressed according to the functional genomics of the individual patient. Thus, a given malocclusion is a stable condition, being arrived at through (a series of) developmental compensation(s). The crowns of teeth are unique, however, in that once fully formed there is no developmental mechanism to change their size or shape. The form of the crowns can change minutely over a period of time through attrition, abrasion and erosion or more quickly through invasive dental interventions. Nevertheless, because of the unyielding properties of enamel, teeth will take up the space made available to them during the course their development ie eruption, and if this space is insufficient then a malocclusion arises. Due to temporo-spatial patterning, given appropriate gene-environmental interactions, teeth will align themselves following the curves of Monson and Spee because of tooth morphology, which has evolved over millennia. In modern societies, however, altered signalling means that teeth end up in positions in which they are not optimal in terms of either function or aesthetics.

In addition to complexity, however, the craniofacial system has adaptability. The framework of the jaws is built from bone which, due to its rich vascularity, has a high degree of plasticity. This means that the facial skeleton can undergo bone remodelling in response to functional stimuli. Thus, while the teeth are actively erupting, their roots and supporting bone are subject to functional stimuli, which mould the final outcome. For example, if an object is placed close to the eruptive pathway, the teeth are in effect deflected into a position different than that defined by temporo-spatial patterning alone. However, the teeth retain their pre-determined form while the enclosing bone is 'deformed' through remodelling. This means that the application of an appropriate signal that remodels the bone can result in the correct re-positioning of the teeth.

Despite the propensity for adaptability, the final arbitrator is stability. The craniofacial system needs to be in balance or equilibrium in accord with functional demands, for example sufficient space for the tongue during mastication, speech and swallowing. Thus, a developmental compromise may be reached with the teeth in a less than ideal position but in a state in which craniofacial homeostasis has been reached. According to the spatial matrix hypothesis, ${ }^{1}$ the craniofacial system will adapt through developmental compensation until a new position of functional stability has been reached. Moreover, specific procedures or treatment protocols may modulate this state of developmental stability to the benefit or detriment of individual patients. G. D. Singh

\section{Portland}

1. Singh G D. On growth and treatment: the Spatial Matrix hypothesis. In McNamara J A Jr (ed). Growth and treatment. Craniofacial growth series. Monograph 41 pp 197-239. Ann Arbor, USA: University of Michigan, 2004.

DOI: 10.1038/bdj.2007.742

\section{Free way space}

Sir, I totally approved the letter from M. J. Trenouth (BDJ 2007; 202: 644) regarding stress, anxiety and TMD and I wonder if he believes, as I do, that an open mouth oral posture is a predisposing cause. My belief is that if the mouth is postured open most of the time then the condyle will remodel to the centre of the joint so that when the teeth come into contact, the condyle is driven back against the posterior fibres of the attachment. This may be why TMD is associated with an increased free way space.

There is a lot of evidence ${ }^{1-3}$ to show that people with teeth apart postures have less satisfactory occlusal contacts and in the past I have suggested that this is due to the tongue resting between the buccal teeth most of the time. ${ }^{4,5}$ This may intrude the buccal teeth, creating poor contacts and allowing the incisors to over-erupt, which is why they may come into contact slightly before the buccal teeth, also driving the mandible back.

I agree with M. J. Trenouth that it is the clenching that causes the damage but could the irregular contacts encourage intermittent clenching, making the oral posture the principal pre-disposing factor? My experience suggests that training the patient to keep their teeth in light contact for four to six hours a day will allow the condyle to remodel forward, making this an effective means of curing TMD, but the patient has to be willing and able to comply. J. Mew By email

1. Ingervall $B$, Minder $C$. Correlation between maximum bite force and facial morphology in children. Angle Orthod 1997; 67: 415-422.

2. Lundeen H C, Gibbs C H. Advances in occlusion. Boston: J. Wright-PSG, 1982.

3. Melsen $B$, Attina L, Suntueri M, Attina A. Relationships between swallowing pattern mode of respiration and developing malocclusion. Angle Orthod 1987; 57: 113-119.

4. Mew J R C. The aetiology of temporomandibular disorders: a philosophical overview. Eur J Orthod 1997; 19: 249-258.

5. Mew J R C. The postural basis of malocclusion: a philosophical overview. Am J Orthod Dentofacial Orthop 2004; 126: 729-738.

DOI: $10.1038 / b d j .2007 .743$

\section{Larvae in the mouth}

Sir, recently we came across a case of oral myiasis, an extremely rare condition, and would like to share it with your readers.

Oral myiasis is caused by the larvae of the fly family sarcophagidae in wounds. Sterilised fly larvae are often 
used to treat stubborn non-healing ulcers by the larvae consuming necrotic tissue and leaving viable tissue behind. ${ }^{1}$

A middle-aged man (Fig. 1) attended The University of the West Indies Dental School and was a known psychiatric patient suffering from schizophrenia and depression. Although the room filled with the pungent smell of rotting flesh, he was totally unaware of what was happening in his mouth.

Several reports of oro-facial myiasis infestations have been found in the literature. ${ }^{2-8}$ Two closely resemble our case. One was in a 20-year-old cerebral palsy female who was noted to have an upper lip swelling ${ }^{2}$ and the other in a secondarily infected noma of a 65-yearold male. ${ }^{3}$

Treatment of myiasis involves physical removal of the larvae and wound cleansing with either topical or systemic medication. Agents used have included ether, chloroform, iodoform or olive oil. ${ }^{2}$ Satisfactory results have been obtained using systemic Ivermectin. ${ }^{2,9}$

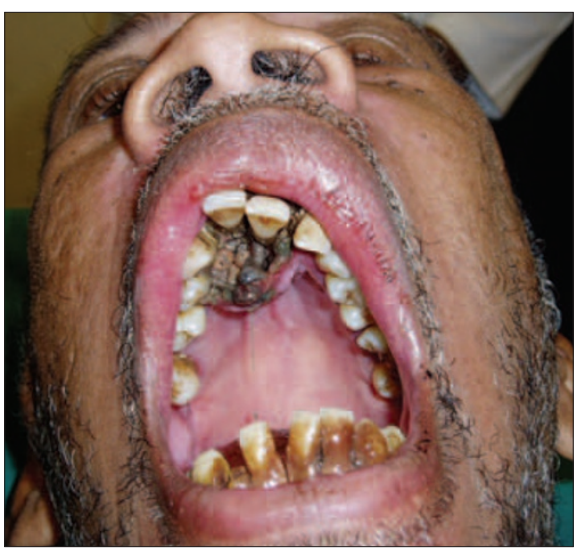

Fig. 1 Appearance of the patient at presentation. Note the presence of larvae in the palate

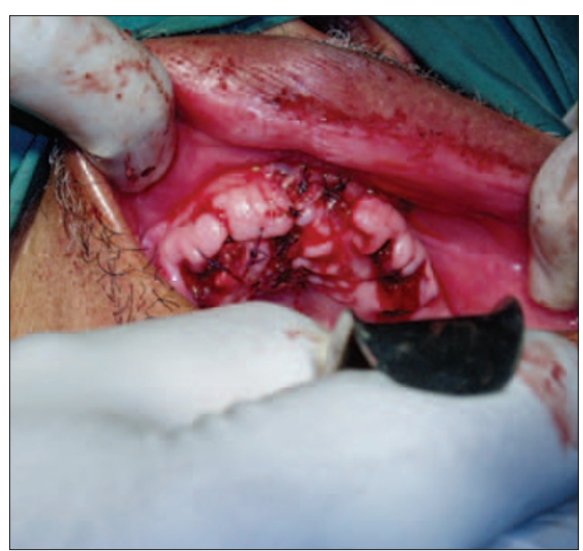

Fig. 2 Removal of the maggots and wound debridement

Our patient received surgical exposure of the affected area under general anaesthesia, removal of the maggots and wound debridement (Fig. 2). The wound was closed with vicryl sutures and the patient was given co-amoxiclav and metronidazole for one week. He was reviewed seven days later and a satisfactory resolution was evident.

J. Philip, Manchester

\section{R. Matthews, Durham}

J. E. Scipio, West Indies

1. Thomas $S$, Jones $M$, Shutler $S$, Jones $S$. Using larvae in modern wound management. J Wound Care 1996; 5: 60-69.

2. Elio R P Shinohara H, Martini M Z de Oliveira Neto $H$ G, Takahashi A. Oral myiasis treated with ivermectin: case report. Braz Dent J 2004; 15: 79-81.

3. A M M Aguiar, C O Enwonwu, F R Pires. Case report: noma (Cancrum Oris) associated with oral myiasis in an adult. Oral Dis 2003; 9: 158-159.

4. Rossi-Schneider T, Cherubini K, Yurgel L S, Salum F, Fiqueiredo M A. Oral myiasis: a case report. J Oral Sci 2007; 49: 85-88.

5. Abdo E N, Sette-Dias A C, Comunian C R, Dutra C E, Aguiar E G. Oral myiasis: a case report. Med Oral Patol Oral Cir Bucal 2006; 11: 130-131.

6. Droma E B, Wilamowski A, Schnur H et al. Oral myiasis: a case report and literature review. Oral Surg Oral Med Oral Pathol Oral Radiol Endod 2007. 103: 92-96.

7. Erol B, Unlu G, Balci K, Tanrikulu R. Oral myiasis caused by hypoderma bovis larvae in a child: a case report. J Oral Sci 2000; 42: 247-249.

8. Gunbay S, Bicakci N, Canda T, Canda S. A case of myiasis gingiva. J Periodontol 1995; 66: 892-895.

9. Fox L M. Ivermectin: uses and impact 20 years on. Curr Opin Infect Dis 2006; 19: 588-593.

DOI: $10.1038 /$ bdj.2007.744

\section{No causal link}

Sir, with reference to the article by Ellis et al. ${ }^{1}$ their conclusion that 'it would not be appropriate to make any assumptions about the links between periodontal disease and cardiovascular disease risk based on this study', is realistic even though the title of the paper Change in cardiac risk status after dental clearance might be considered slightly contradictory.

The paper by Taylor et al. ${ }^{2}$ does have a logical title Full-mouth tooth extraction lowers systemic inflammatory/ thrombotic markers of cardiovascular disease. However, their conclusion that the 'findings suggest that treatment of periodontitis may reduce the risk of cardiovascular disease' is not clearly supported by the paper.

Also cited by Ellis et al. is the expert working group advice as regards reliability of markers of inflammation in cardiovascular disease. ${ }^{3}$ It was their opinion that if CRP levels are to be considered in the staging of cardiovascular disease status then this should only be in individuals where active infection, systemic inflammatory processes, or trauma have abated. Now periodontal disease was not mentioned specifically but then nor were any other inflammatory conditions. At the moment it is our understanding that CRP remains a marker of inflammatory disease (a marker has no causal relationship with 
the condition it is associated with). CRP is not at the moment considered a risk factor (a risk factor has a proven causal link with a condition). Both Ellis et al. and Taylor et al. have demonstrated that the CRP level can be reduced if an inflammatory condition (periodontal disease) is treated. While CRP remains a marker of inflammatory disease, which may well include cardiovascular disease, the extraction of teeth in an attempt to reduce cardiovascular risk cannot yet be supported. Until a causal link between periodontal disease and cardiovascular disease is more clearly demonstrated this will remain the case. N. Malden

By email

1. Ellis J S, Averley P A, Preshaw P M et al. Change in cardiovascular risk status after dental clearance. $\mathrm{Br}$ Dent J 2007: 202: 543-544.

2. Taylor B A, Tofler G H, Carey H M et al. Full-mouth tooth extraction lowers systemic inflammatory and thrombotic markers of cardiovascular risk. J Dent Res 2006; 85: 74-78.

3. Pearson T A, Mensah G A, Alexander R W et al. Markers of inflammation and cardiovascular disease. Circulation 2003; 107: 499-511.

DOI: 10.1038/bdj.2007.745

\section{Treating the cause}

Sir, I read Bill Kellner-Read's 'Opinion' article (BDJ 2007; 202: 593-595) with great interest. I have known Bill for almost 30 years, ever since he played a major role in my personal quantum leap from treating 'the white bits only' to treating complete people, yet I am still taken aback by his clarity of thought and the depth of his insight.

There is ever-increasing evidence that we dentists need to raise our game as well as our vision, and to pay more than lip service to the concept that our patients are whole people who need to be assessed and treated as such. It is no longer enough to trot out the old adages about dentists diagnosing and impacting on systemic diseases through oral examination, true and important though they may be. We need to learn a whole lot more about how dentistry connects physically with the cranium, the cervical spine and rest of the spine. We need to learn that if the cervical spine is compromised, then so is the lumbar spine, through the intricate structural and neurological connections. We have to acquire a whole new set of additional values that encompass the concept of what is becoming known as structural dentistry.

The scientific evidence for these phenomena may well be absent from the dental literature, but it is present in abundance in the osteopathy and chiropractic literature.

All joints have two bony components and dentistry alone cannot comprehensively treat temporomandibular joint disorders, because we do not yet have the skills to treat the other (temporal bone) half of the joint. We require a craniopath to identify and correct, for example, the misalignment of the temporal bones and the glenoid fossae that prevents the TM joints from functioning in synchrony.

We need to be part of the growing understanding that orthodontic malocclusion is a cranial event, caused by imbalances in cranio-facial growth and development, and that if we treat these patients purely dentally, we are not only missing the point of what we are doing, but we are possibly committing the patient to a high probability of relapse.

Treating the result does not address the cause.

Understanding the functionality of the cranial bones has been denied us as a profession through narrow undergraduate training because of the accepted convention of handing down the information from one generation of dental students, and their teachers, to the next.

The academic side of this process has prevented teachers from looking at other disciplines such as chiropractic and osteopathy simply because they do not get published in our own literature, and therefore in effect they do not exist. In any case, to teach such stuff to their students would almost certainly be seen as heresy.

Curiously, of all the health care professions, dentistry is ideally-placed to grasp the principles of cranial bone motion; we only have to see that cranial suture fibres are essentially the same as periodontal fibres. Ipso facto they must surely perform similar functions - micro-movement and shock-absorption. Once this is realised, one is well on the way to understanding, and believing, that the cranial bones can actually move.
I am pleased that the $B D J$ now permits us the right to publish these views so that these fascinating ideas are out in the open and up for discussion. I am ever hopeful that the mandarins of the dental establishment may yet be persuaded to reconsider their viewpoints. N. Stimson Isle of Wight DOI: 10.1038/bdj.2007.746

\section{Virtually impossible}

Sir, given its widespread occurrence in our diet, it is virtually impossible to avoid daily exposure to fluoride. It therefore seems highly improbable that $\mathrm{H}$. Keanie's patient is allergic to fluoride (Fluoride allergy BDJ 2007; 202: 507).

The possibility of allergy to fluoride has been investigated by eminent experts in the field of allergy both in the UK and in the US. Reviews by Challacombe, ${ }^{1} \mathrm{NHMRC}^{2}$ and $\mathrm{NRC}^{3}$ all concluded that the studies undertaken do not support claims that fluoride is allergenic. They considered the weight of evidence to show that fluoride is unlikely to produce hypersensitivity or other immunological effects.

According to Challacombe ${ }^{1}$ there have been no confirmed cases of allergy to fluoride or of positive skin testing in humans or in animals and there is no increased reporting of allergies of any type with increasing fluoride use. Fluoride is also found in many foods and drinks, and there are no reports of reactions of an allergic nature to fluoride in such commonly encountered substances - for example tea and tinned fish.

Finally, the Medical Research Coun$\mathrm{cil}^{4}$ considered the weight of evidence to show that fluoride is unlikely to produce hypersensitivity or other immunological effects.

S. Jones

By email

1. Challacombe S J. Does fluoridation harm immune function? Community Dent Health 1996; 13 suppl 2: 69-71.

2. NHMRC. The effectiveness of water fluoridation (Report D6). Australia: National Health and Medical Research Council Canberra, 1991.

3. NRC. Health effects of ingested fluoride. Washington DC: National Academy Press, 1993

4. Medical Research Council. Working group report: water fluoridation and health. London: MRC, 2002.

DOI: 10.1038/bdj.2007.747 